\title{
INFLUENCE OF HUMAN MILK OLIGOSACCHARIDES ON ADHERENCE OF BIFIDOBACTERIA AND CLOSTRIDIA TO CELL LINES
}

\author{
Sarka Musilova*, Nikol Modrackova, IVo Doskocil, ROMAN SVEJSTIL and \\ VOJTECH RADA
}

Department of Microbiology, Nutrition and Dietetics, Faculty of Agrobiology, Food and Natural Resources, Czech University of Life Sciences Prague, Prague, Czech Republic

(Received: 17 December 2016; accepted: 17 May 2017)

\begin{abstract}
Adhesion of gut bacteria to the intestinal epithelium is the first step in their colonization of the neonatal immature gut. Bacterial colonization of the infant gut is influenced by several factors, of which the most important are the mode of delivery and breast-feeding. Breast-fed infants ingest several grams of human milk oligosaccharides (HMOs) per day, which can become receptor decoys for intestinal bacteria. The most abundant intestinal bacteria in vaginally delivered infants are bifidobacteria, whereas infants born by cesarean section are colonized by clostridia. The influence of HMOs on the adhesion of five strains of intestinal bacteria (three bifidobacterial strains and two clostridial strains) to mucus-secreting and non-mucus-secreting human epithelial cells was investigated. Bifidobacterium bifidum 1 and Bifidobacterium longum displayed almost the same level of adhesion in the presence and absence of HMOs. By contrast, adhesion of Clostridium butyricum 1 and 2 decreased from $14.41 \%$ to $6.72 \%$ and from $41.54 \%$ to $30.91 \%$, respectively, in the presence of HMOs. The results of this study indicate that HMOs affect bacterial adhesion and are an important factor influencing bacterial colonization of the gut. Adhesion of the tested bacteria correlates with their ability to autoaggregate.
\end{abstract}

Keywords: human milk oligosaccharides, bifidobacteria, clostridia, cell lines, autoaggregation

\section{Introduction}

Bacterial colonization of the infant gut is influenced by several factors, of which the most important are the mode of delivery and breast-feeding. Breast milk is a complex source of nutrients for infants and has protective effects against

*Corresponding author; E-mail: musilovas@af.czu.cz 
diseases while their immune system matures [1-3]. This defensive function is attributed to antimicrobial peptides and proteins and human milk oligosaccharides (HMOs). Infants ingest several grams of HMOs daily and these are the first prebiotics they are exposed to [4]. These carbohydrates guide the development of the neonatal gut and shape the intestinal microbiota toward a health-promoting community of bifidobacteria, which are the predominant gut bacteria of vaginally delivered and breast-fed infants [5]. However, the predominant bacteria in infants delivered by cesarean section are clostridia, which can be gradually replaced by bifidobacteria during the breast-feeding period [6]. HMOs assist implantation of bifidobacteria into the intestines of infants. Microbial adhesion is the first step in colonization of the neonatal intestinal tract. It has been explored whether autoaggregation of bacteria increases their ability to adhere. Del Re et al. [7] investigated the relationship between autoaggregation and the adhesion ability of Bifidobacterium longum. The aim of this study was to evaluate the influence of HMOs on the adhesion of bifidobacteria and clostridia to mucus-secreting HT29MTX and non-mucus-secreting Caco- 2 cell lines. We hypothesized that bifidobacteria would adhere better than clostridia in the presence of HMOs and that their ability to adhere would correlate with their autoaggregation properties.

\section{Materials and Methods}

\section{Bacterial strains}

Bifidobacterium longum subsp. infantis was isolated from the probiotic product Infloran (Laboratory Pharmaceutical S.I.T., S.r.l., Italy). Bifidobacterium bifidum 1 and 2 were isolated from fecal samples of 3-month-old vaginally delivered breast-fed infants. Bifidobacteria were isolated using selective TPY agar (Scharlau, Spain) modified by the addition of mupirocin $(100 \mathrm{mg} / \mathrm{L})$ and acetic acid $(1 \mathrm{~mL} / \mathrm{L})$ according to the method described by Rada and Petr [8] and identified by subspecies-specific polymerase chain reaction $[9,10]$. Clostridium butyricum 1 and 2 were isolated from fecal samples of 2-month-old breast-fed infants born by cesarean section using reinforced clostridial medium agar (Oxoid, UK) according to Vlková et al. [10]. Fresh fecal samples of infants were aseptically transferred to tubes containing Wilkins-Chalgren broth (Oxoid), transported to the laboratory, and analyzed within $2 \mathrm{~h}$. The samples were serially diluted in the Wilkins-Chalgren broth under anaerobic conditions and analyzed using selective media. All strains were identified by fluorescence in situ hybridization kits with specific probes (C. butyricum group and Bifidobacterium spp.; Ribo Technologies, the Netherlands). They were further characterized by the API 
50 CHL biochemical test (bioMérieux, Marcy l'Etoile, France) and their autoaggregation properties were determined according to Vlková et al. [10].

\section{Aggregation assay}

Bacteria were cultivated in Wilkins-Chalgren broth at $37{ }^{\circ} \mathrm{C}$ for $24 \mathrm{~h}$. The tubes were shaken and absorbance at $600 \mathrm{~nm}\left(\mathrm{~A}_{600}\right)$ was measured in the upper part of the suspension at 0, 0.5, 1, 2, 3, 4, and $5 \mathrm{~h}$ [10]. Aggregation ability (Agg) was expressed as the Agg percentage after $5 \mathrm{~h}$ of incubation, which was calculated using the following formula: Agg $\%=\left[1-\left(\mathrm{A}_{600}\right.\right.$ of upper suspension at time $t / \mathrm{A}_{600}$ of total bacterial suspension at time 0$\left.)\right] \times 100$ at different time points [7].

\section{Cell culture}

The human colorectal adenocarcinoma cell line Caco-2 and the mucussecreting cell line HT29-MTX-E12 were obtained from Sigma-Aldrich (Prague, Czech Republic). The cell lines were cultured in Dulbecco's modified Eagle's medium (DMEM) supplemented with 20\% fetal bovine serum, $1 \%$ non-essential amino acids, $100 \mu \mathrm{g} / \mathrm{mL}$ penicillin, and $100 \mu \mathrm{g} / \mathrm{mL}$ streptomycin. Cultures were incubated at $37{ }^{\circ} \mathrm{C}$ in a humidified atmosphere of $5 \%(\mathrm{v} / \mathrm{v}) \mathrm{CO}_{2}$ and $95 \%$ air. The medium was changed every 2 days, and the cells were subcultured at $80 \%$ confluency every week. All solutions were purchased from Sigma-Aldrich.

\section{HMOs preparation}

HMOs were isolated and purified from breast milk samples obtained from volunteer mothers as described by Rockova et al. [11]. Stock solution of HMOs $(c=23.5 \mathrm{~g} / \mathrm{L})$ were prepared using phosphate-buffered saline (PBS) and syringe microfilters (pore size $0.2 \mu \mathrm{m}$; Whatman ${ }^{\circledR}$ Anotop ${ }^{\circledR}$ IC and LC; Whatman GmbH, Germany) and used immediately after preparation.

\section{Adhesion assays}

The adhesion assay was performed using a previously described method [12] with slight modifications. Caco-2 and HT29-MTX cells were seeded in NUNC 24-well culture plates at a density of $3.6 \times 10^{4}$ and $0.4 \times 10^{4}$ cells per well, respectively, and grown for $14 \pm 1$ days until confluent at $37^{\circ} \mathrm{C}$ in a humidified atmosphere of $5 \%(\mathrm{v} / \mathrm{v}) \mathrm{CO}_{2}$ and $95 \%$ air. The culture medium was changed 
every 2 days. Before adding the bacterial suspension, the cell monolayers were washed with PBS to remove antibiotics. Thereafter, $900 \mu \mathrm{L}$ of HMO solution was added to the washed cell monolayers, whereas $900 \mu \mathrm{L}$ of DMEM (without supplements) was added to the control wells. The final concentration $(c=21.5 \mathrm{~g} / \mathrm{L})$ of HMOs was the same as in the human colostrum. Subsequently, $100 \mu \mathrm{L}$ of the bacterial suspension was added. For each strain, controls and treated wells were prepared in triplicate. Then, the plates were incubated at $37{ }^{\circ} \mathrm{C}$ for $1 \mathrm{~h}$ in an atmosphere of $5 \% \mathrm{CO}_{2}$. After incubation, the cell layers were gently washed three times with PBS to remove non-adherent bacteria. Finally, the cell layers were lysed by the addition of $300 \mu \mathrm{L}$ of $1 \%$ Triton X-100 (Sigma-Aldrich) per well for $1 \mathrm{~min}$, followed by the addition of $700 \mu \mathrm{L}$ of PBS. The lysed suspension of cells with viable adhered bacteria was diluted to a bacterial concentration of $1 \times 10^{7} \mathrm{cfu} / \mathrm{mL}$.

The bacterial counts of the collected samples were determined using the plate method after serial dilution on cultivation media (Wilkins-Chalgren anaerobe agar, Oxoid). All plates were anaerobically incubated at $37^{\circ} \mathrm{C}$ for $48 \mathrm{~h}$ and then bacteria were counted.

Adhesion of bacteria was evaluated according to the following formula:

$$
\text { Adhesion }=(\text { bacterial count of sample } / \text { bacterial count of control }) \times 100
$$

where the control represents $100 \%$ adhesion.

\section{Statistical analyses}

Differences in adherence and autoaggregation of bacteria were evaluated by performing multiple range comparisons using Duncan's multiple range test [this procedure was used as a precaution against the known type I error inflation problem that arises when many (necessarily interdependent) comparisons are tested]. Significance was set at $P \leq 0.05$. All statistical analyses were performed using STATGRAPHICS Centurion XVII (Manugistics, Rockville, MD, USA).

\section{Results}

Autoaggregation of bacteria was examined on the basis of their sedimentation characteristics (Table I). The tested strains either autoaggregated (Agg+) or did not autoaggregate (Agg-) according to the phenotypes described by Del Re et al. [7]. B. bifidum 1 autoaggregated, had a high Agg percentage of nearly $50 \%$ $(49.90 \%)$ after $4 \mathrm{~h}$ and formed a precipitate, resulting in a clear solution, which correlated with its ability to adhere to cell lines in the presence of HMOs. 
Table I. Autoaggregation (Agg \%) of the tested strains (measured after $5 \mathrm{~h}$ )

\begin{tabular}{lr}
\hline Strain & \multicolumn{1}{c}{ Agg $\%$} \\
\hline Bifidobacterium bifidum 1 & $49.90 \pm 1.33$ \\
Bifidobacterium bifidum 2 & $8.55 \pm 1.18$ \\
Bifidobacterium longum subsp. infantis & $1.51 \pm 0.09$ \\
Clostridium butyricum 1 & $11.90 \pm 1.64$ \\
Clostridium butyricum 2 & $5.70 \pm 0.34$ \\
\hline
\end{tabular}

Note: Values are means of triplicates \pm standard deviations.

C. butyricum 1 demonstrated weak aggregation (Agg+, 11.90\%). The other tested strains (two bifidobacterial strains and one clostridial strain) were unable to aggregate (Agg-, $\leq 10 \%$ ) and constant turbidity was observed in the tubes. The adhesion of all five strains to human Caco-2/HT29-MTX cells was examined. The ability of $B$. bifidum 1 and $B$. longum to adhere did not differ significantly between medium containing HMOs and medium lacking of HMOs (Figure 1). B. bifidum 1 and $B$. longum displayed almost the same level of adhesion in the presence of HMOs $(32.59 \% \pm 4.81 \%$ and $37.59 \% \pm 4.97 \%$, respectively) and the absence of HMOs $(38.91 \% \pm 6.83 \%$ and $39.43 \% \pm 5.47 \%$, respectively) (Figure 1). B. bifidum 2 was not able to autoaggregate $(8.55 \pm 1.18)$ and its ability to adhere

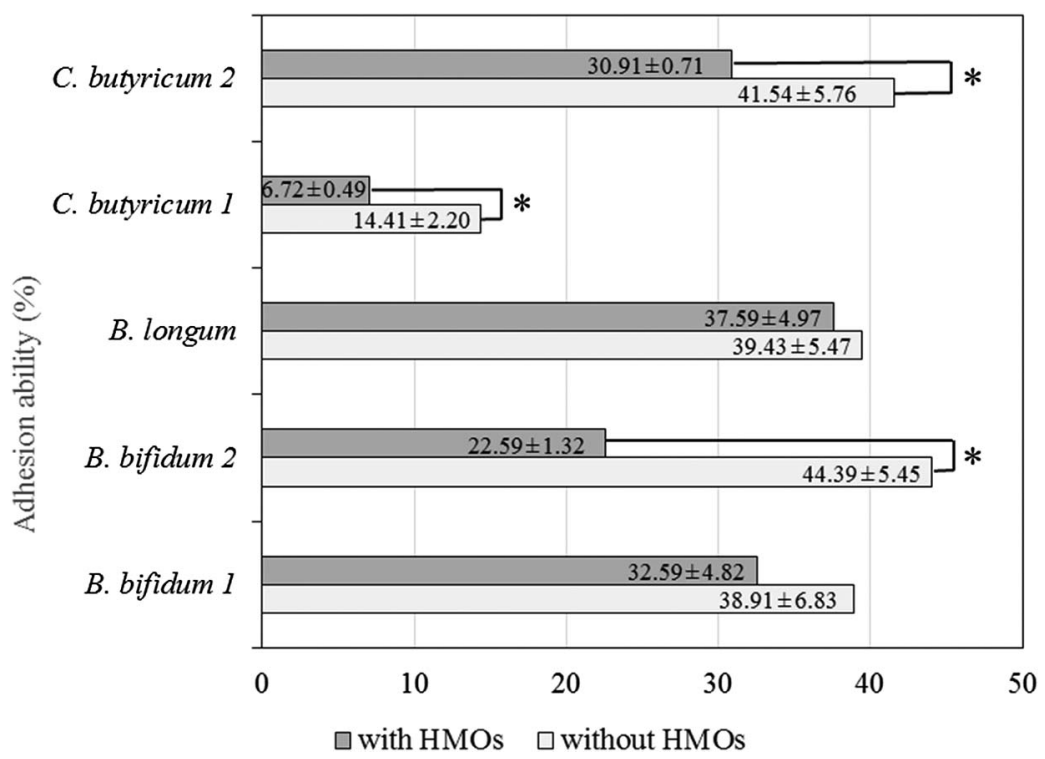

Figure 1. Ability of the tested strains to adhere to cell lines with HMOs and without HMOs. *Values are significantly different $(P<0.05)$ 
to cell lines was similar as to $B$. bifidum 1 without HMOs and lower with HMOs. By contrast, $C$. butyricum 1 and 2 and B. bifidum 2 adhered better in medium lacking of HMOs than in medium containing HMOs.

\section{Discussion}

The Agg test is often used for preliminary screening to identify potentially adherent bacteria [13]. One of the tested strains (B. bifidum 1) had a high Agg and was able to adhere equally well in the presence and absence of HMOs. On the other hand, B. longum did not aggregate and its adhesion ability was similar in the presence and absence of HMOs, as in the case of B. bifidum 1. Bacterial adhesion to the intestinal mucosa is important for colonization of the infant gut. The bacterial adhesion to intestinal mucosa is one of the most important properties for colonization of the infant gut. It belongs to many health benefits of probiotic bacteria [14]. Oligosaccharides can influence the adhesion of bacteria. Inconsistent results have been reported between tested oligosaccharides and bacterial strains. In general, oligosaccharides have antiadhesive effects on gut bacteria. Chitooligosaccharides inhibit the adhesion of pathogenic Escherichia coli [15].

Kadlec and Jakubec [16] also tested several prebiotic oligosaccharides and reported that fructooligosaccharides and galactooligosaccharides generally decrease adhesion of the tested probiotic strains (Lactobacillus, Lactococcus, Enterococcus, and Bifidobacterium spp.). It is well known that bifidobacteria are also able to utilize different carbon source such are raffinose-series oligosaccharides present in soya beans and other legumes oligosaccharides [17]. Altamimi et al. [18] first investigated the antiadhesive effect of oligosaccharides on mixed bacteria imitating the gut microbiota in vitro. They reported that clostridial strains are the most strongly influenced bacteria in mixed cultures. In this study, clostridial strains were most influenced by HMOs.

In addition to their prebiotic effect, HMOs also have inhibitory effects on adhesion of pathogens, such as Campylobacter jejuni, enteropathogenic E. coli, Salmonella enterica serovar Fyris, and Pseudomonas aeruginosa to the intestinal human cell line Caco-2 [19]. Some HMOs act as molecular decoys by inhibiting the potential pathogens.

Therefore, we tested the influence of HMOs on common bacteria of the infant gut microbiota. Adhesion of some bifidobacterial strains was not influenced by prebiotic HMOs, while other bacteria were less able to adhere in the presence of HMOs. The ability of four of the five tested strains to adhere to epithelial cells correlated with their ability to autoaggregate, similar to the findings of a previous study [7]. 


\section{Conclusions}

HMOs may act as antiadhesive molecules and therefore prevent adhesion not only of potential pathogens but also of potential probiotic microorganisms. The ability to adhere to the epithelial surface of the gut seems to be strain-specific. The impact of HMOs is also strain-specific, but bacteria that can autoaggregate probably adhere better. Aggregation is an advantage, but not a requirement, for bacterial adhesion to the mucus layer.

\section{Acknowledgements}

This study was supported by a grant from the Czech Science Foundation (14-31501P and CIGA 20142049).

\section{Conflict of Interest}

The authors declare that there is no conflict of interest regarding the publication of this paper.

\section{References}

1. Kramer, M. S., Aboud, F., Mironova, E., Vanilovich, I., Platt, R. W., Matush, L., Igumnov, S., Fombonne, E., Bogdanovich, N., Ducruet, T.: Breastfeeding and child cognitive development: New evidence from a large randomized trial. Arch Gen Psychiatry 65, 578 (2008).

2. Lawrence, R. M., Pane, C. A.: Human breast milk: Current concepts of immunology and infectious diseases. Curr Probl Pediatr Adolesc Health Care 37, 7 (2007).

3. Reilly, J. J., Armstrong, J., Dorosty, A. R., Emmett, P. M., Ness, A., Rogers, I., Steer, C., Sherriff, A.: Early life risk factors for obesity in childhood: Cohort study. BMJ 330, 1357 (2005).

4. Chaturvedi, P., Warren, C. D., Buescher, C. R., Pickering, L. K., Newburg, D. S.: Survival of human milk oligosaccharides in the intestine of infants. In Newburg, D. S. (ed): Bioactive Components of Human Milk. Springer, New York, 2001, pp. 315-323.

5. Fallani, M., Young, D., Scott, J., Norin, E., Amarri, S., Adam, R., Aguilera, M., Khanna, S., Gil, A., Edwards, C. A., Doré, J.: Intestinal microbiota of 6-week-old infants across Europe: Geographic influence beyond delivery mode, breast-feeding, and antibiotics. J Pediatr Gastroenterol Nutr 51, 77-84 (2010).

6. Musilova, S., Rada, V., Vlkova, E., Bunesova, V., Nevoral, J.: Colonisation of the gut by bifidobacteria is much more common in vaginal deliveries than caesarean sections. Acta Paediatr 104, 184-186 (2015). 
7. Del Re, B., Sgorbati, B., Miglioli, M., Palenzona, D.: Adhesion, autoaggregation and hydrophobicity of 13 strains of Bifidobacterium longum. Lett Appl Microbiol 31, 438-442 (2000).

8. Rada, V., Petr, J.: A new selective medium for the isolation of glucose non-fermenting bifidobacteria from hen caeca. J Microbiol Methods 43, 127-132 (2000).

9. Sakata, S., Kitahara, M., Sakamoto, M., Hayashi, H., Fukuyama, M., Benno, Y.: Unification of Bifidobacterium infantis and Bifidobacterium suis as Bifidobacterium longum. Int J Syst Evol Microbiol 52, 1945-1951 (2002).

10. Vlková, E., Rada, V., Šmehilová, M., Killer, J.: Auto-aggregation and co-aggregation ability in bifidobacteria and clostridia. Folia Microbiol 53, 263-269 (2008).

11. Rockova, S., Nevoral, J., Rada, V., Marsik, P., Sklenar, J., Hinkova, A., Vlkova, E., Marounek, M.: Factors affecting the growth of bifidobacteria in human milk. Int Dairy J 21, 504-508 (2011).

12. Jensen, H., Grimmer, S., Naterstad, K., Axelsson, L.: In vitro testing of commercial and potential probiotic lactic acid bacteria. Int J Food Microbiol 153, 216-222 (2012).

13. Collado, M. C., Meriluoto, J., Salminen, S.: Measurement of aggregation properties between probiotics and pathogens: In vitro evaluation of different methods. J Microbiol Methods 71, 71-74 (2007).

14. Collado, M. C., Gueimonde, M., Sanz, Y., Salminen, S.: Adhesion of selected Bifidobacterium strains to human intestinal mucus and the role of adhesion in enteropathogen exclusion. J Food Prot 68, 2672-2678 (2005).

15. Quintero-Villegas, M. I., Aam, B. B., Rupnow, J., Sørlie, M., Eijsink, V. G., Hutkins, R. W.: Adherence inhibition of enteropathogenic Escherichia coli by chitooligosaccharides with specific degrees of acetylation and polymerization. J Agric Food Chem 61, 2748-2754 (2013).

16. Kadlec, R., Jakubec, M.: The effect of prebiotics on adherence of probiotics. J Dairy Sci 97, 1983-1990 (2014).

17. Havas, P., Kun, S., Perger-Mészáros, I., Rezessy-Szabó, J. M., Nguyen, Q. D.: Performances of new isolates of Bifidobacterium on fermentation of soymilk. Acta Microbiol Immunol Hung 62, 643-675 (2015).

18. Altamimi, M., Abdelhay, O., Rastall, R.: Effect of oligosaccharides on the adhesion of gut bacteria to human HT-29 cells. Anaerobe 39, 136-142 (2016).

19. Weichert, S., Jennewein, S., Hüfner, E., Weiss, C., Borkowski, J., Putze, J., Schroten, H.: Bioengineered 2'-fucosyllactose and 3-fucosyllactose inhibit the adhesion of Pseudomonas aeruginosa and enteric pathogens to human intestinal and respiratory cell lines. Nutr Res 33, 831-838 (2013). 